\title{
PRICE DEFLATORS, THE TRUST FUND FORECAST, AND SOCIAL SECURITY SOLVENCY
}

\author{
Barry Bosworth \\ CRR WP 2010-12 \\ Date Released: October 2010 \\ Date Submitted: September 2010 \\ Center for Retirement Research at Boston College \\ Hovey House \\ 140 Commonwealth Avenue \\ Chestnut Hill, MA 02467 \\ Tel: 617-552-1762 Fax: 617-552-0191 \\ http://crr.bc.edu
}

Barry Bosworth is a senior fellow at the Brooking Institution. The research reported here was performed pursuant to a grant from the U.S. Social Security Administration (SSA) funded as part of the Retirement Research Consortium (RRC). The opinions and conclusion expressed are solely those of the author and do not represent the opinions or policy of SSA, any agency of the federal government, the RRC, the Brookings Institution, or Boston College. I am indebted to Sveta Milusheva for research assistance.

(C) 2010, by Barry Bosworth. All rights reserved. Short sections of text, not to exceed two paragraphs, may be quoted without explicit permission provided that full credit, including $($ ) notice, is given to the source. 


\section{About the Center for Retirement Research}

The Center for Retirement Research at Boston College, part of a consortium that includes parallel centers at the University of Michigan and the National Bureau of Economic Research, was established in 1998 through a grant from the Social Security Administration. The Center's mission is to produce first-class research and forge a strong link between the academic community and decision makers in the public and private sectors around an issue of critical importance to the nation's future. To achieve this mission, the Center sponsors a wide variety of research projects, transmits new findings to a broad audience, trains new scholars, and broadens access to valuable data sources.

\section{Center for Retirement Research at Boston College}

Hovey House

140 Commonwealth Avenue

Chestnut Hill, MA 02467

phone: 617-552-1762 fax: 617-552-0191

e-mail: crr@bc.edu

crr.bc.edu

Affiliated Institutions:

The Brookings Institution

Massachusetts Institute of Technology

Syracuse University

Urban Institute 


\begin{abstract}
The differential in the growth rates of the GDP price deflator and the CPI-W has a significant effect on the projected actuarial balance of the Social Security trust fund. When the CPI-W grows at a faster rate than the GDP deflator, projected benefits increase relative to the growth in program income. This study is directed toward measuring the sources of the difference in the two growth rates and its likely magnitude in the future. The study concludes that there no basis for expecting a consistent difference between the rate of consumer price inflation and that for the overall economy as measured by the GDP price deflator. However, because of differences in the methods of computing the two price indexes, the growth in the CPI-W can be expected to exceed the increase in the GDP deflator by about 0.2 percent per year. This differential is about half that currently assumed within the Social Security Trustees report.
\end{abstract}




\section{Introduction}

Pure price inflation has only a small long-run effect on the solvency of the Social Security system. At the beginning of each year, the taxable wage ceiling, existing benefits, and the parameters of new benefit awards are all adjusted on the basis of the prior year's change in the Consumer Price Index for Urban Wage Earners and Clerical Workers (CPI-W). ${ }^{1}$ Assuming that higher inflation affects wages and consumer prices equally, it initially raises contributions into the trust fund, and after a one-year lag it raises benefit payments by a similar proportionate amount. The net effect depends on the relative magnitudes of contributions and benefit payments, but it is generally small.

However, the trustees' projections of Social Security finances incorporate two measures of inflation. The estimates of future economic growth are based on assumptions about future economy-wide gains in productivity and labor compensation. Those projections are drawn from data in the U.S. national accounts and they are constructed using the GDP price deflator, the broadest and most-commonly used measure of price change at the level of the total economy. However, because the annual adjustments to the Social Security system are indexed to changes in CPI-W, projections of the system's future solvency depends to some extent on the relationship between these two indicators of price change. If the CPI-W rises faster than the GDP deflator, it increases the projected cost of the system relative to tax revenues.

The objective of this paper is to examine the reasons for the variation in the difference between the GDP price deflator and the CPI-W and to provide some guidance about its future evolution. The framework used to make the trust fund projections is summarized in the following section. The second section examines the historical differences between the two measures of inflation in greater detail. The analysis highlights some inconsistencies between the projections of labor productivity and real wages that may contribute to an unduly pessimistic outlook for the system's finances. In particular, methodological changes in the computation of the CPI-W have sharply reduced the difference between it and price indexes of the national accounts. Thus, it is argued that the current projections of the system's finances are unduly pessimistic in projecting too rapid a rate of growth in the CPI-W relative to the GDP deflator, and thereby overstating increases in future benefit costs.

\footnotetext{
${ }^{1}$ More specifically, the adjustment of December benefits (paid in January) is based on the year-over-year rate of change in the average of $\mathrm{CPI}-\mathrm{W}$ in the third quarter of the calendar year.
} 


\section{Actuarial Projections}

Each year the trustees of the Old Age and Survivors Insurance (OASI) and Disability Insurance (DI) trust funds report on the current and projected financial status of the two programs. A similar analysis is prepared for the Hospital Insurance (HI) portion of the Medicare program. Their evaluation incorporates projections that extend the funds' financial balance on an annual basis for 75 years into the future. The projections are built up from underlying demographic and economic assumptions about the future evolution of the U.S. economy. The demographic assumptions provide the basis for projecting the future workforce and the number of Social Security beneficiaries.

On the economic side, the projections of the system's finances are strongly influenced by the growth in earnings per worker. Total earnings essentially determine payroll tax revenues; and while benefits are also indexed to the earnings growth, the effect on benefit expenditures is smaller than the effect on tax revenues. First, there is a lag between the years in which the worker pays taxes and the receipt of benefits. Second, after the initial benefit payment, future adjustments are indexed not to wages, but to the slower growing CPI. Therefore, the financial balance is sensitive to variations in wage growth.

The projection for the growth in earnings per worker is built up from estimates of the growth in labor productivity (output per worker hour) and a set of linkages that shows the relationship between growth in labor productivity $(\mathrm{GDP} / \mathrm{H})$ and the growth in real earnings per employed person(W/E). ${ }^{2}$ The estimates of productivity growth are based on estimates of GDP that use the GDP price deflator to adjust for variations in the rate of overall price inflation. The linkages include: labor compensation as a share of GDP (COMP/GDP), the proportion of earnings in compensation (W/COMP), and hours per worker (H/E). In addition, the price indexation of the OASDI system is legally tied to the CPI-W, which has a narrower focus on the market basket of consumer products purchased by workers. Thus, the ratio of output prices to consumption prices $\left(\mathrm{P}_{\mathrm{gdp}} / \mathrm{CPI}\right)$ is included as one of the linkages.

$$
\frac{W}{E}=\left(\frac{G D P}{H}\right) \times\left\{\left(\frac{C O M P}{G D P}\right) \times\left(\frac{W}{C O M P}\right) \times\left(\frac{H}{E}\right) \times\left(\frac{P_{g d p}}{C P I}\right)\right\}
$$

\footnotetext{
${ }^{2}$ In the social security framework the earnings of the self-employed are included with employee compensation and wages.
} 
The basic economic assumptions are summarized in Table 1. Each annual report shows three alternative scenarios, using low-cost (optimistic), intermediate, and high-cost (pessimistic) combinations of the assumptions. The lower portions of the table highlight some alternative scenarios based on the historical averages that are the primary basis for the projections.

Productivity growth is the key determinant of overall economic growth and a frequent area of debate about expectations for the future. The Trustees' Report is heavily influenced by past trends, and the current projection of 1.7 percent per year is close to the average of the past 40 years.

Table 1. Long-range Economic Projections for Social Security

Average annual percentage rates of change

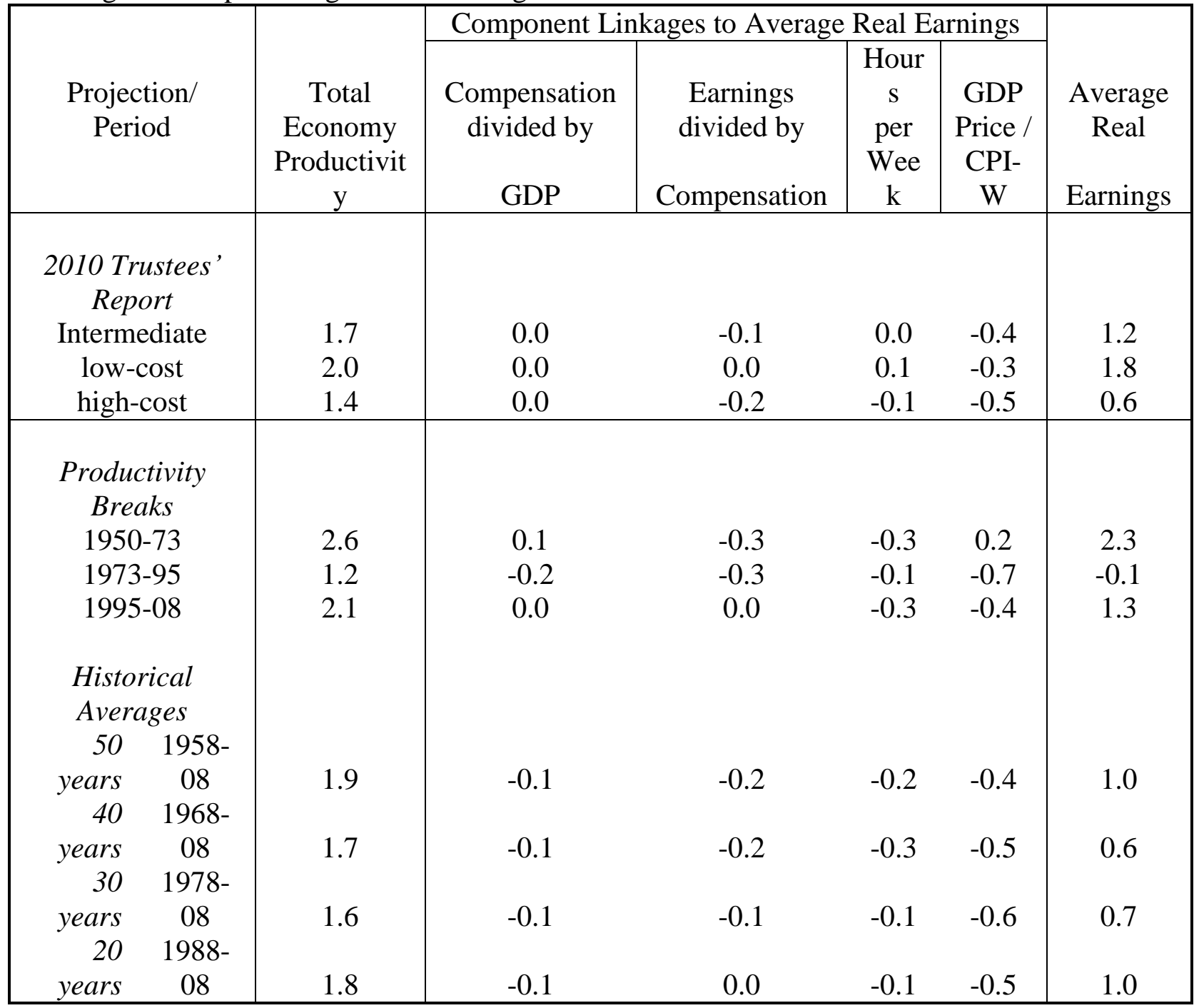

Source: The 2010 Annual Report of the Board of Trustees of the Federal Old-Age and Survivors Insurance and Federal Disability Insurance Trust Funds (Baltimore MD: Social Security Administration, 2010), table V.B1. 
One of the most consistent features of the projections is the shortfall in the growth of workers' real earnings relative to the gains in their productivity. Over the past four decades, real earnings have grown at an average annual rate of 1.0 percent compared to an average increase in productivity of 1.9 percent per year. Some of the underlying causes of the shortfall are quite understandable. The share of labor compensation in GDP has been remarkably stable in the historical data and is not projected to change significantly in the future. However, the increase in employment taxes for Social Security and Medicare and rising employer costs of health insurance and pensions have all contributed to a decline in earnings (taxable payroll) as a share of total compensation. In addition, a higher level of productivity and incomes has been associated with a shortening of the work week, a trend that has moderated in recent years and is projected to continue at a gradual pace in the future. Finally, about half of the shortfall between the growth of productivity and real wages can be traced to the more rapid increase in CPI-W (the prices paid by workers) compared to $\mathrm{P}_{\text {gdp }}$ (the prices of the products that workers produce). The reasons for the faster rate of increase in consumer prices are less-well understood and considerable controversy surrounds the projection that it will continue in the future.

\section{GDP versus Consumer Prices}

As noted in the introduction, the differential between the rate of increase in the GDP price deflator and CPI-W has a major effect on the projected actuarial balance of the system. When the CPI-W grows at a faster rate than the GDP deflator, benefits increase relative to the growth in program income. The differential is projected at 0.4 percent per year in the intermediate alternative of Table 1 , and the trustees' report imposes a narrow range of 0.3 to 0.5 across the three alternative scenarios; but each tenth of a percentage point increase in the CPI-W above that of the GDP deflator raises the system's long-run deficit by about 0.14 percent of taxable wages (Trustees’ Report, 2010, p.167).

The difference in the two price measures reflects both differences in the composition of the aggregate of products purchased by consumers compared to the composition of total GDP, and the different methods of computing average rates of price change in the national accounts and the CPI-W. The relative importance of these two factors can be highlighted by first comparing the GDP and consumption price indexes within the national accounts where the methodology is identical, and then contrasting the consumption price index with the CPI-W. 
Output and consumption prices in the national accounts

The ratio of the price deflator for personal consumption (PCED) relative to that of GDP, both of which are derived from the national accounts, is shown in Figure 1 for the period of 1950 to 2009. These two indexes are based on identical methods and reflect only differences in the composition of the two market baskets. They are also generally viewed as the most sophisticated and best measures of price inflation. They incorporate up-to-date measures of the composition of both consumer expenditures and total GDP. Within this common framework, the relative price of consumption has remained remarkably stable over the past 60 years. Although the ratio declined over the first half of the period from 1950 to 1980, it has been slowly trending up over the last three decades at a rate of about 0.1 percent per year. However, there would seem to be little basis for projecting a sustained increase or decrease in the ratio in future years.

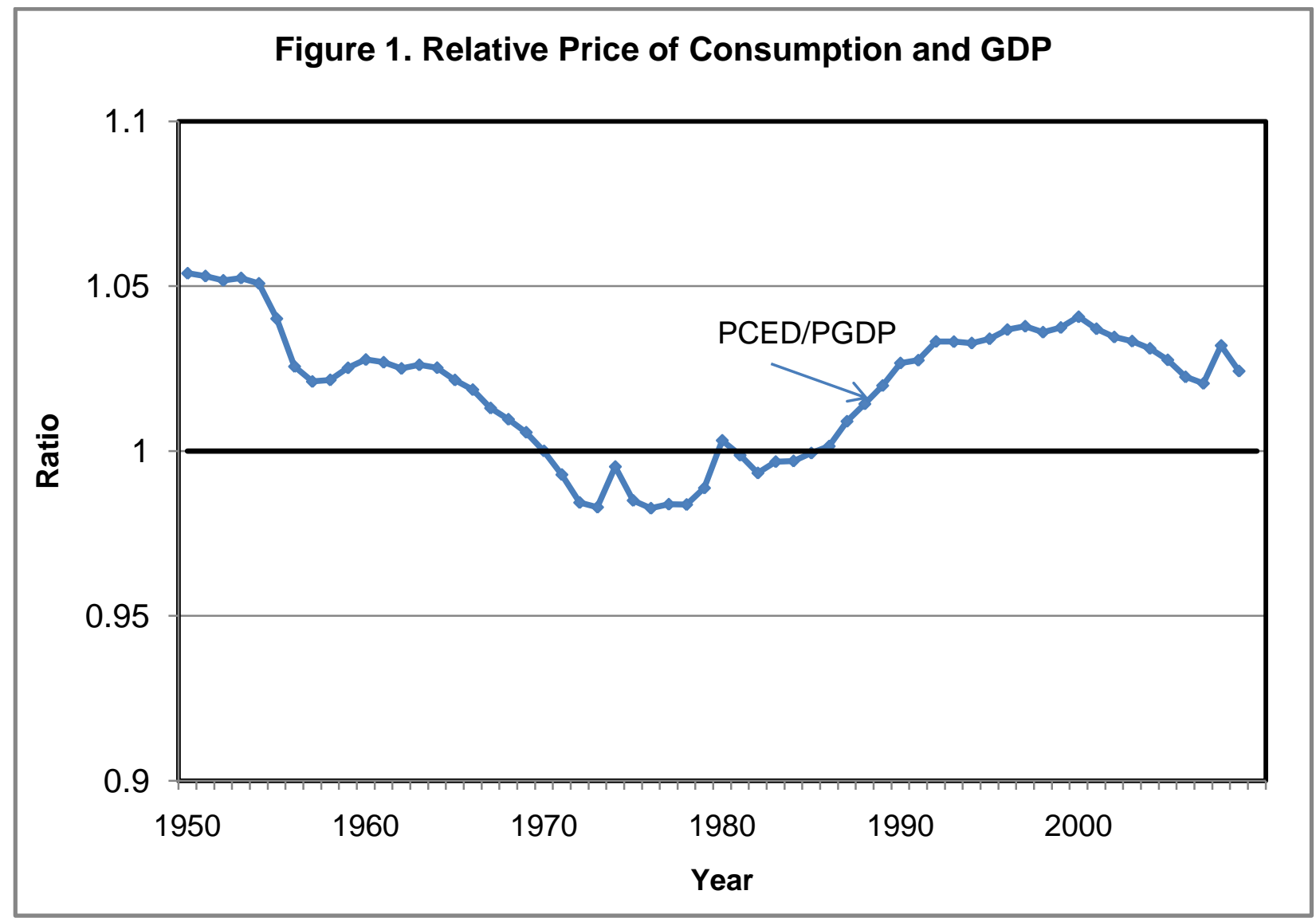

Source: Table 1.1.4 of the national accounts and author's calculations.

Since consumer expenditures account for more than two-thirds of GDP, the two price indexes have much in common. The largest potential differences derive from the inclusion of imported goods in consumption whereas GDP is limited to domestic production. In addition, 
direct market measures of the prices of government expenditures, a component of GDP, are not available, and the price deflators are largely constructed from measures of their input cost and an assumption of no improvements in productivity within the government sector.

Direct comparisons of the price indexes for comparable components of consumption and GDP in the national accounts are largely limited to broad categories. The relative prices of services, durable and nondurable goods are displayed in Figure 2. That disaggregation suggests that the pre-1980 decline in the relative price of consumer expenditures was concentrated in services, and more specifically a fall in the relative price of housing services up to about 1975 . In recent years the price of consumer services has closely paralleled the corresponding measure for services in GDP and the relative price has been very stable. In contrast, the category of

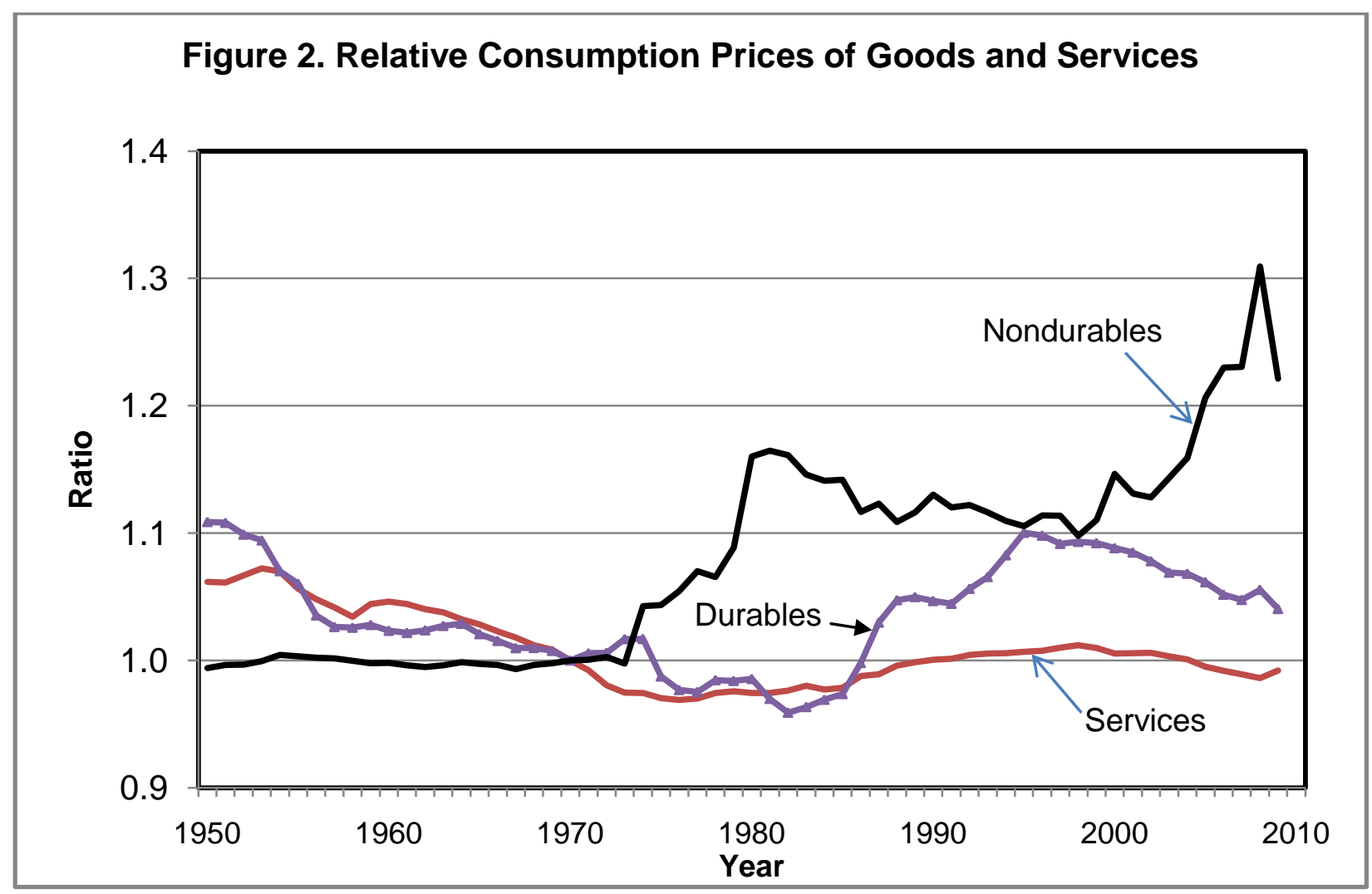

Source: tables 1.2.4 and 2.3.4 of the national accounts and author's calculations. Indexes constructed with a base of 1970 equal to 1.0. Relative price refers to price of component in consumption expenditures compared to GDP.

consumer goods is more heterogeneous and the items purchased for consumption are often quite different than those purchased by the government or used for investment or export. A significant portion of consumption goods are also imported. As a result, the variations in relative prices are larger. For example, durable goods' prices have had similar rates of low or negative price 
change at the level of consumer goods and for the broader economy because both contain large portions of electronic goods, where relative prices have fallen rapidly in recent decades. Nondurables (including food, clothing, and energy) have had more disparate patterns of relative price trends, and substantial increases in energy prices (largely imported) have more than offset a steady decline in the relative price of apparel. Nondurables also represent a larger weight in consumption than in total GDP.

An alternative perspective on the differences in the composition of personal expenditures and GDP can be constructed from the national input-output table. A summary of the industry composition of consumption and total GDP in 2002 is shown in Table 2. The largest differences result from the exclusion of construction and the government sectors from consumption and the greater weights attached to owner-occupied housing and health care as components of consumption. Manufactured goods account for a larger share of consumption than of GDP because of the sizable role of imported goods. This is particularly true for petroleum products. It is also striking that computer and other high-technology products whose price declines have been so rapid in recent years are equally important in consumption and GDP as a whole. However, if the government sector, a producer of services, is combined with private services, the industrial structure of consumption and GDP seem broadly comparable, and there is no large disparity that is closely connected to expectations of a sustained change in relative prices.

In summary, the analysis of price trends within the national accounts provides only weak evidence of a secular rise in the relative price of consumption products. Over the full period of 1950 to the present, output and consumption prices have increased at nearly identical rates. However, the relative price of consumption has been rising at a slightly faster rate since the mid1970s, largely due to the increased cost of energy. However, a comparison of the underlying industrial composition of consumption and GDP provide little basis for anticipating a consistent pattern of change in their relative prices in future years. Perhaps energy prices will continue to outpace the rise in other prices, and a decline in the relative value of the dollar would push up the price of imports. Both of these factors would tend to raise the relative price of consumption, but their influence is neither large nor assured. 
Table 2. Industry Distribution of Personal Consumption Expenditures and GDP

\begin{tabular}{|l|c|c|c|}
\hline \multicolumn{1}{|c|}{ Industry } & $\begin{array}{l}\text { Personal } \\
\text { consumption } \\
\text { expenditures }\end{array}$ & $\begin{array}{l}\text { Total } \\
\text { inal } \\
\text { uses }\end{array}$ & $\begin{array}{l}\text { PCE- } \\
\text { GDP }\end{array}$ \\
\hline Agriculture, forestry, fishing and hunting & 0.6 & 0.4 & 0.3 \\
\hline Mining & 0.0 & -0.6 & 0.6 \\
\hline Utilities & 2.3 & 1.6 & 0.7 \\
\hline Construction & 0.0 & 8.2 & -8.2 \\
\hline Manufactures & $\mathbf{1 6 . 6}$ & $\mathbf{1 3 . 0}$ & $\mathbf{3 . 6}$ \\
\hline Food and Beverage Products & 4.4 & 3.0 & 1.4 \\
\hline Apparel & 1.3 & 0.3 & 1.0 \\
\hline Pharmaceuticals and medicines & 1.4 & 0.6 & 0.8 \\
\hline Petroleum and coal products & 0.9 & 0.5 & 0.4 \\
\hline Other Non-Durable Goods & 2.5 & 1.4 & 1.0 \\
\hline Computer, Audio, and semiconductor equipment & 0.7 & 0.8 & 0.0 \\
\hline Electronic Instruments & 0.1 & 0.6 & -0.5 \\
\hline Aerospace products and parts & 0.0 & 0.6 & -0.6 \\
\hline Other Durable Goods & 5.3 & 5.2 & 0.1 \\
\hline Services & $\mathbf{7 9 . 3}$ & $\mathbf{6 2 . 6}$ & $\mathbf{1 6 . 7}$ \\
\hline Retail trade & 14.6 & 12.3 & 2.2 \\
\hline Finance, insurance, real estate, rental, and leasing & 11.8 & 9.5 & 2.4 \\
\hline Owner-occupied housing & 12.8 & 9.0 & 3.8 \\
\hline Professional and business services & 2.1 & 3.6 & -1.5 \\
\hline Educational services, health care, and social assistance & 18.7 & 13.2 & 5.6 \\
\hline Arts, entertainment, recreation, and accommodation & 7.6 & 5.4 & 2.3 \\
\hline Other services, except government & 11.7 & 9.7 & 2.0 \\
\hline Government & 0.6 & 15.7 & -15.1 \\
\hline Other inputs & 0.4 & -1.0 & 1.5 \\
\hline SOurce: Computed by the anthor from the & & & \\
\hline
\end{tabular}

Source: Computed by the author from the 2002 Input-Output table of the Bureau of Economic Analysis.

\section{Alternative Consumer Price Indexes}

The BLS publishes two primary measures of consumer prices: the CPI-U, which is intended to be representative of the expenditure patterns of all urban consumers, and the CPI-W, which covers a subset for urban wage earners and clerical workers. The latter index is representative of only about one-third of the U.S. population but is mandated by law to be used as the basis for annual adjustments to the Social Security system. Despite the differences in the size of their covered populations, the CPI-U and the CPI-W typically show very similar changes and the annual differences have averaged less than 0.1 of a percentage point over the past two 
decades. ${ }^{3}$ However, the methods used to compute the CPI have changed in important ways over the years, and the historical values have not been revised to incorporate the new methods.

Instead, BLS researchers have constructed an unofficial research version of the CPI-U, extending back to 1978, that is representative of a consistent application of the latest methods (Stewart and Reed, 1999).

The most important methods change in the CPI was a conversion to a measure of the rental equivalence for homeownership in 1983. Previously, the CPI incorporated a measure of the cost of purchasing a home-the purchase price plus mortgage interest payments. That version of the index was very sensitive to changes in mortgage interest rates, and the changeover to a rental equivalency concept in 1983 occurred only after a period of large increases in interest rates. With the adoption of the rental concept, home purchase is treated as an investment, and for consumption purposes homeowners are viewed as renting from themselves. The rental cost of owner-occupied housing is assumed to rise in step with similar rental properties. This concept is closely related to the approach used in the national accounts. The CPI-W was converted to the new formula in 1985. In subsequent years, both CPI indexes underwent a series of additional changes to incorporate other methodological improvements. ${ }^{4}$

For this study, the research series of the CPI-U can be extended back to 1967 by using an earlier experimental index that was designed to incorporate the rental equivalence concept for housing (Gillingham and Lane, 1982). The rate of change was further reduced by 0.2 percent per year to reflect other methodological changes that were introduced after 1997. For the years before 1967, there is no alternative measure based on rental costs, but home prices and interest rates fluctuated over a narrow range. Thus, the estimate of the research series is limited to reducing the annual changes in the published CPI-U index by 0.2 percent. ${ }^{5}$ Comparable estimates of a research series for CPI-W were constructed by assuming that its annual changes

\footnotetext{
${ }^{3} \mathrm{CPI}-\mathrm{U}$ and CPI-W differ only in the weights that are applied to the underlying basic indexes. There are 8,018 basic indexes, the product of 211 expenditure categories and 38 geographic areas. The weights are derived from a survey of consumer expenditures. CPI-W has a significantly higher weight on commodities and energy and correspondingly less on services. Thus, the differences in the rates of price change are largest during periods of sharp commodity price fluctuations, such as 2007-2009.

${ }^{4}$ The most recent summary of the methodological improvements is available in Reed and Stewart (2009).

${ }^{5}$ The extension back to the years before 1978 was constructed by the author since no published estimate is available from the BLS, but a similar measure is discussed in the report of the 2007 Technical Panel on Assumptions and Methods. The estimates for the years before 1978 are very approximate but they reflect the major methodological changes.
} 
would differ from those of its published version in the same proportion as for the research and published versions of the CPI-U.

A summary of the differences between the published CPI-W series and the estimate based on a consistent methodology is shown in Figure 3. The differences averaged 0.4 to 0.8 percent per year in the 1970s and early 1980s when the official index included home purchase. It increased again during the 1990s when BLS introduced some other formula changes. However, the modifications over the last decade have had a negligible effect.

\section{Figure 3. Average Annual Difference Between CPI-W and the Research Series Using Current Methods}

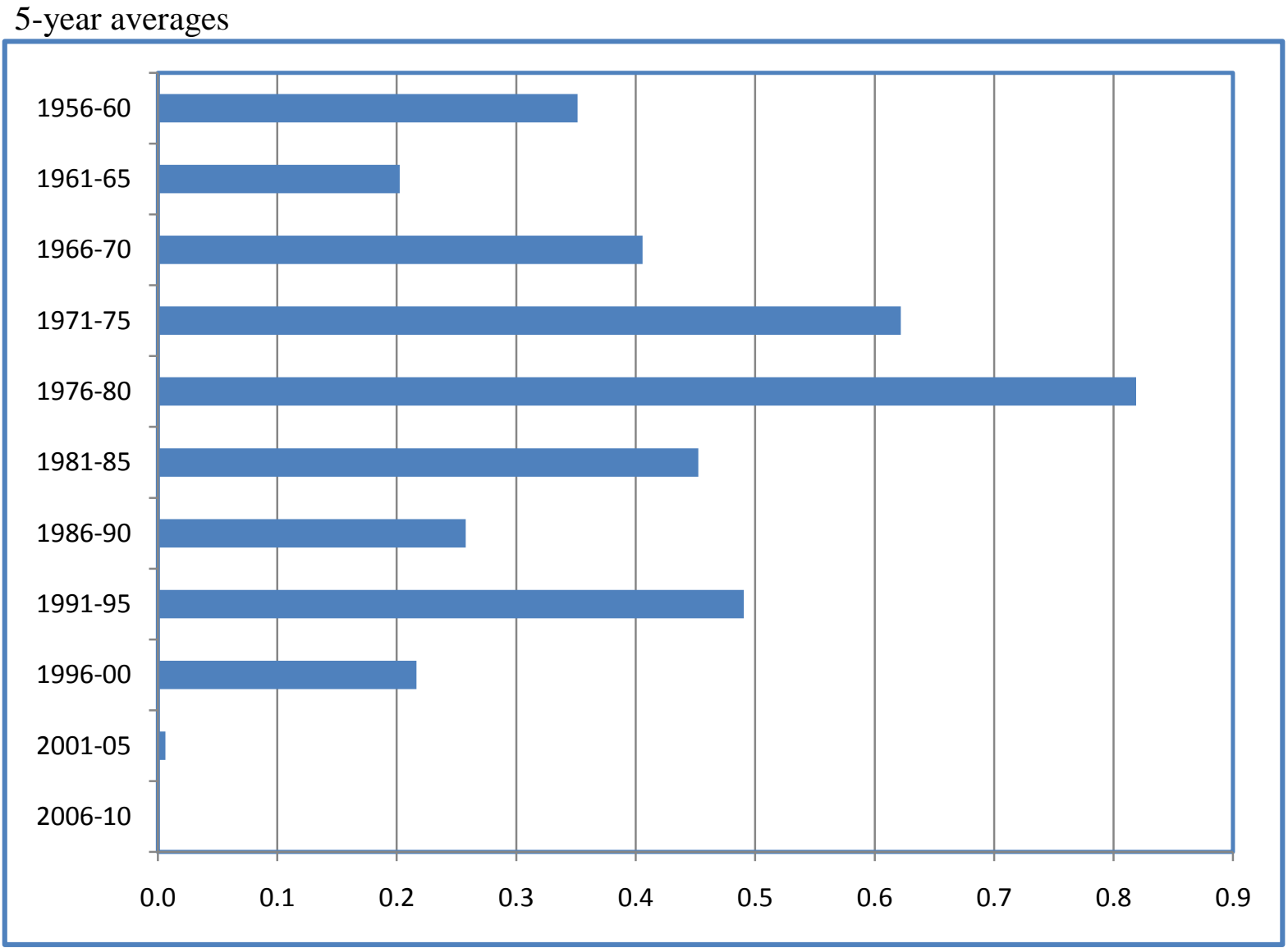

Source: The research version of the CPI-W is constructed by the author as described in the text.

The ratios of the CPI-W to the PCED, using both the published version and the historically-consistent series are shown in Figure 4. The large difference between the published measure and the research series highlights the importance of the methodological improvements 
and the extent to which they have reduced the reported rate of price inflation in the CPI. The ratio of the research series of the CPI-W to the PCED fluctuates within a narrow range of \pm 0.3 percent over the past half century, but the rates of change still show significant differences over shorter periods. The research series version of the CPI-W rose more slowly over the period of 1950 up to about 1995, but it has been rising more rapidly in the past decade.

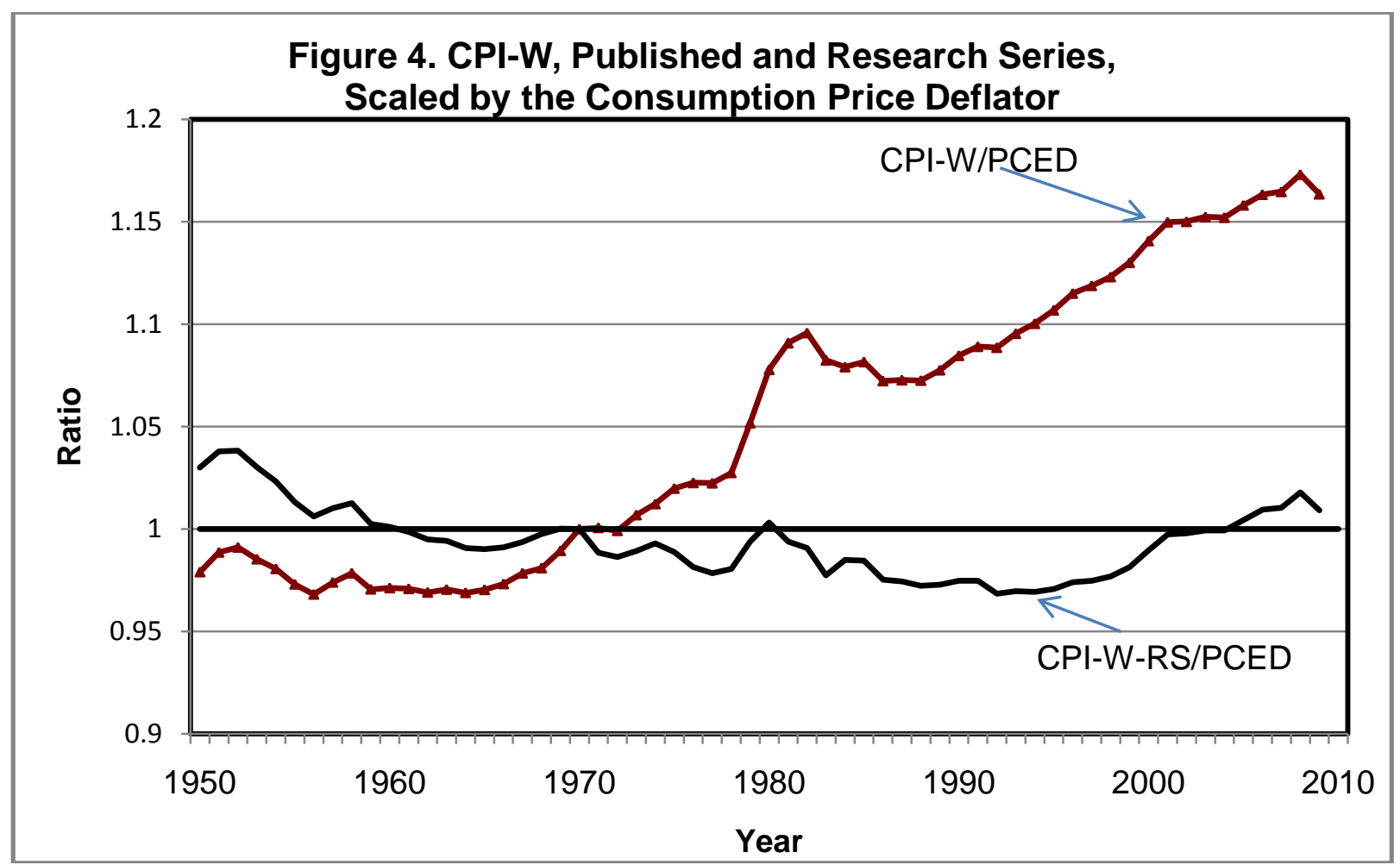

Source: Constructed by the author as explained in text.

As indicated in Figure 5, the research version of the CPI-W and the PCED record similar long-term changes relative to the GDP price deflator-a fall in the relative price of consumption up to 1980 and an increase over the past three decades. However, the pattern is somewhat exaggerated in the CPI-W; the annual rate of increase since 1975 has exceeded that of the GDP price deflator by 0.06 percent per year, and 0.17 percent since 1990 . This growth in the differential is, however, much less than the 0.3-0.5 percent rate projected for the future in the Trustees' Report (see Table 1). 


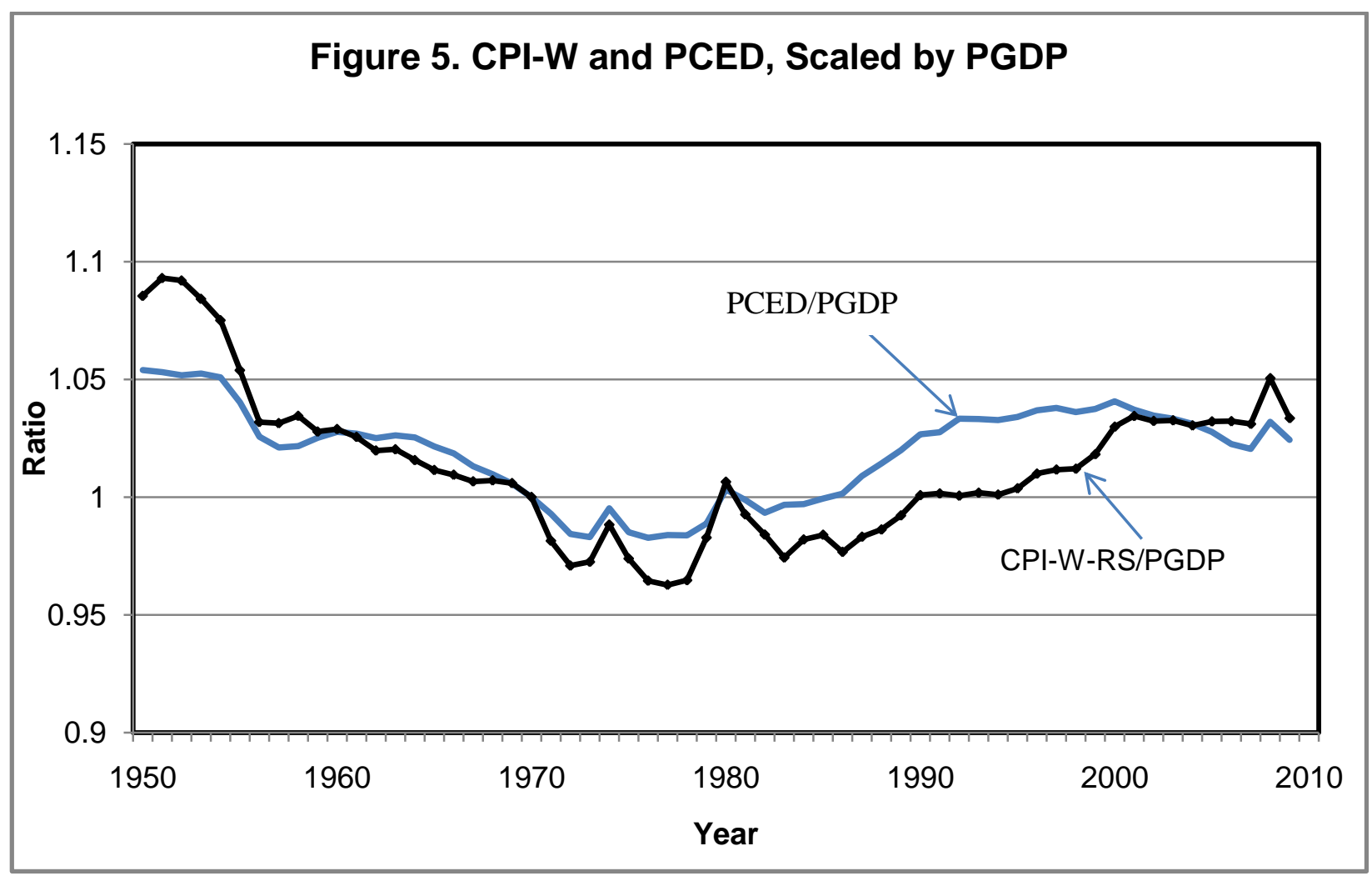

Source: Constructed by the author as explained in text.

\section{Reconciling the CPI and the PCE Deflator}

Despite the method changes in the construction of the CPI indexes, there are still significant differences in the construction of the CPI and the price deflators of the national accounts; and in recent years the differences have attracted attention for reasons that go beyond the indexation of Social Security benefits. In particular, the focus on inflation targeting as an approach to monetary policy has stimulated discussions of the CPI and PCED as alternative measures of inflation (Clark, 1999, and Meyer, 2008). The divergences between the indexes have been explored empirically in a series of papers: Triplett (1981), Fixler and Jaditz (2002), McCulley and others (2007) and Garner and others (2006). That research identified three broad categories of divergence: formula differences, differences in the weights, and differences in the scope of the two indexes.

Formula differences. The CPI uses a Laspeyres price index to measure price change in a fixed market basket of consumption items. Historically, the weights were changed on an infrequent cycle of about 10 years. Since 1987, the weights are updated every two years, and new procedures have been introduced to update other aspects of the index on a more continuous 
basis. The updated weights mitigate but do not eliminate the substitution bias introduced when consumers shift the pattern of their purchases away from products whose relative prices have increased.

In contrast, the national accounts use a Fisher index for aggregation. It is a geometric average of a Laspeyres (beginning-of-period weights) and a Paashe (end-of-period weights), and it is designed to capture more completely the effects of substitution among product groups in response to relative price changes. The level of the index is computed by chaining the individual Fisher indexes for successive periods. In general, the chained Fisher index will record smaller price increases than the Laspeyres. In the national accounts, the price measures are periodically revised in line with improved estimates of the weights. However, the avoidance of revisions is a major objective of the CPI, and the updating of the weights on a two-year cycle is seen as a practical compromise.

Differences in weights. After the introduction of the changes in the methods of computing the CPI in the 1980s and 1990s, the most significant remaining differences arise from the very different sources of information on the composition of household consumption. The information on the composition of consumers' expenditures in the national accounts is largely drawn from business surveys. In contrast, the weights in the CPI are obtained from the Consumer Expenditure Survey. The CES is an ongoing survey in which individual households are asked to participate for five consecutive quarters. After allowing for nonresponse, about 7,000 usable interviews are obtained in each quarter and they are aggregated over two years to reach a sufficient sample size on which to base changes in the weights for the CPI. The differences between the composition of expenditures in the CES and the PCE have been evaluated in a series of BLS papers, the most recent of which is Garner and others (2009).

The CES appears to encounter severe problems of under-reporting of many categories of expenditures, relative to the estimates in the national accounts. While some of the discrepancies may result from problems with the allocation of expenditures in the national accounts, various consistency checks limit the magnitude of those errors and suggest the discrepancies are largely reflective of recall errors in the household survey. Both sources provide very similar estimates for large expenditure items. For example, they are in fairly close agreement with respect to expenditures on housing. But because nearly everything else is underestimated in the CES, the CPI has a final weight on housing that is about twice that of the PCED. It also appears that the discrepancies are increasing over time (Garner and others (2009). 
These aspects are highlighted in Table 3, which shows the ratio of consumer expenditures in the two reports for selected years. Even when the analysis is restricted to closely comparable items, the ratio of expenditures as reported in the survey fell steadily from the corresponding estimate of the national accounts, from 86 to 81 percent between 1992 and 2007. There is also evidence that the survey is under-representative of households at the top of the income distribution. The discrepancies have also had a major impact on the estimates of macroeconomic trends. In the interval of 1985-2008, when the ratio of consumption to disposable income in the national accounts was rising by more than 5 percentage points, the corresponding ratio in the CES fell dramatically, implying a huge increase in the household saving rate.

\begin{tabular}{|c|c|c|c|c|}
\hline & 1992 & 1997 & 2002 & 2007 \\
\hline All Items & 67.4 & 64.7 & 60.6 & 59.1 \\
\hline Comparable items & 86.1 & 84.7 & 82.0 & 81.0 \\
\hline Comparable Durables & 87.7 & 79.8 & 75.3 & 78.7 \\
\hline Comparable Nondurables & 69.3 & 66.9 & 62.9 & 61.4 \\
\hline Comparables Services & 104.4 & 103.3 & 101.9 & 220.1 \\
\hline Housing & 113.6 & 115.0 & 113.8 & 118.8 \\
\hline Comparable items less housing & 73.4 & 70.3 & 66.3 & 62.5 \\
\hline All Items less housing & 57.3 & 54.1 & 49.6 & 46.8 \\
\hline
\end{tabular}

Source: Garner and others (2009), table 2.

Differences in scope. The coverage of the CPI and the personal consumption price deflator differ most significantly for medical care. The CPI includes only out-of-pocket medical expenses. The national accounts record third-party payments by private and public insurers as transfers to households and the payments to health providers are included as part of personal consumption expenditures. In addition, the national accounts include a range of products, such as financial services, whose prices are imputed because of a lack of observable price measures. Personal consumption also includes nonprofit institutions whose spending (approximately 2.5 percent of the total PCE) has a different composition than that of households. Finally, The CPI indexes are limited to urban households. McCully and others (2007) estimated the noncomparable items to be 26 percent of PCE and 6 percent for the items included in the CPI.

Summary measures. Summaries of the differences between the CPI and the PCED, using the methodology outlined in McCully and others (2007), are now reported on the web site 
of the Bureau of Economic Analysis on a regular basis. The comparisons begin in 2002, after the adoption of the major methodological changes in the CPI. The formula differences are estimated by re-computing the PCED with fixed weights. The effect of the differences in scope are measured by re-computing each index after excluding those items that are out of scope for the other. The influence of the weight differences is obtained by re-computing the indexes using the difference in the weights for comparable items multiplied by their price change. There are also some residual differences because a few items in PCE rely on measures of price change from sources other than the CPI. For example, prices from the Producer Price Index are used for medical care and airline fares. The two source agencies also differ in their methods of computing the seasonal factors. The residual differences are, however, typically quite small.

Table 4. Reconciliation of Changes in the CPI and PCED, 2002-2010:2 average annual percent change

PCE Chain-type price index (percent change)

Less: Formula effect

Equals: PCE fixed-weight price index

Less: Weight effect

Rent of shelter

Energy

Other
2.36

$-0.17$

2.54

$-0.51$

$-0.38$

$-0.17$

0.04

Less: Scope effect - PCE price index items out-of-scope of the CPI

0.70

Medical

Financial services

0.09

Other

0.24

Plus: Scope effect - CPI items out-of-scope of the PCE price index
Medical
0.22
Other
0.14
0.07

Less: Other effects

$-0.02$

Equals: CPI (percent change)

2.57

Source: Table 9.OU from the BEA web site:

http://www.bea.gov/national/nipaweb/nipa_underlying/SelectTable.asp\#S9 
The differences between the CPI and the PCED are summarized in Table 4 for the period of 2002 to the second quarter of 2010, which represents a period after the introduction of most of the changes in the methods of computing the CPI. Thus, as might be expected, the contribution of the formula differences has become small, increasing the average annual rate of change in the CPI by about 0.2 percentage points. ${ }^{6}$ However, the differences in the weights added 0.5 percentage points, largely due to the greater CPI weight assigned to housing and energy whose prices have risen faster than the average. In contrast, the differences in the scope of the two indexes typically reduce the rate of change in the CPI because it excludes large portions of medical care and financial services. Over the nine years for which we have data, the scope effects have offset nearly all of the weight effect, limiting the difference between the two price indexes to the formula effect. However, the larger estimates for the individual components indicate a greater potential for future divergences since there is no reason to assume that the weight and scope differences will continue to be offsetting. The large positive value of the weight effect is largely due to the greater weight attached to shelter in the CPI and the negative scope effect is a reflection of the small weight on medical care. The prices of both of these items have been rising faster than the price index for consumption as a whole; and thus, to some extent their effects on the indexes have neutralized one another. That pattern is likely to continue for medical care but the relative future price of housing is more uncertain. The basic result of the disaggregate analysis is to suggest a much wider range of potential uncertainty about future divergences between the rates of change in the GDP deflator and the CPI than we would infer from the historical pattern of the two aggregate indexes.

\section{Summary Implications}

The above review suggests that there is no strong basis for believing that the rate of consumer price inflation will consistently depart from that of the overall economy as measured by the GDP price deflator. The similarity is most evident in the comparison of the consumer expenditure price deflator and the GDP price deflator where they are both based on identical methodologies; but is also apparent in the comparison of the CPI-W and the national accounts price indexes when the CPI-W is computed with a consistent up-to-date methodology. However,

\footnotetext{
${ }^{6}$ An alternative computation, using a chained version of the CPI, suggests that the formula effect could be as large as 0.3; but, as explained in McCully and others (2007), it would be partially offset by a different estimate of the weight effect.
} 
the differential between the rate of change of the CPI-W and the GDP deflator can be expected to average about 0.2 percent per year because of a continuing formula difference-a fixed-weight Laspeyres index for the CPI-W versus the chained price indexes of the national accounts that incorporate weight changes on a more current basis.

The 2007 Technical Panel on Assumptions and Methods examined the differential rate of inflation between the GDP price deflator and the CPI-W and reached a similar conclusion that the differential is most likely to average about 0.2 percent per year. The panel recommended that future Trustees' Reports revise the number down from the 0.4 percent that was used in 2007. The annual reports have thus far rejected that advice and the 2009 and 2010 reports continued to assume a differential of 0.4 percent for the intermediate projection. 


\section{References}

The 2010 Annual Report of the Board of Trustees of the Federal Old-Age and Survivors Insurance and Federal Disability Insurance Trust Funds (Baltimore Md: Social Security Administration, 2010)

Clark, Todd. 1999. "A comparison of the CPI and the PCE price index," Federal Reserve Bank of Kansas City Economic Review, Issue III: 15-29.

Fixler, Dennis and Ted Jaditz. 2002. "An Examination of the Difference Between the CPI and the PCE deflator,” Bureau of Labor Statistics Working Paper 361, June.

Garner, Thesia I., George Janini, William Passero, Laura Paszkiewicz, and Mark Vendemia. 2006. "The CE and the PCE: a comparison," Monthly Labor Review, September, pp. 2046.

Garner, Thesia, Robert McClellan, and William Passero. 2009. "Strengths and Weaknesses of the Consumer Expenditure Survey from a BLS Perspective," paper presented at National Bureau of Economic Research, Summer Institute, and Conference on Research on Income and Wealth (July).

Gillingham, Robert, and Walter Lane. 1982. "Changing the treatment of shelter costs for homeowners in the CPI," Monthly Labor Review, Vol. 105, No. 6: 9-14.

McCully, Clinton P., Brian C. Moore, and Kenneth J. Stewart. 2007. "A Reconciliation between the Consumer Price Index and the Personal Consumption Expenditures Price Index," Bureau of Economic Analysis and Bureau of Labor Statistics, Washington, D.C.

Meyer, Lawrence H. 2008. "The CPI and the PCE Price Index: A (Former) Policymaker's Perspective," presented at the annual meeting of the AEA Committee on Economic Statistics, January 5.

Reed, Stephen B. and Kenneth J Stewart. 2009. "Consumer Price Index Series Using Current Methods, 1978-2008," in Bureau of Labor Statistics, CPI Detailed Report, April 2009: 210 .

Stewart, Kenneth J and Stephen B Reed. 1999. "Consumer Price Index Research Series Using Current Methods, 1978-98," Monthly Labor Review, June, pp. 29-38.

Technical Panel on Assumptions and Methods.(2007. Report to the Social Security Advisory Board. Washington, D.C.(October).

Triplett, Jack E. 1981. "Reconciling the CPI and the PCE Deflator," Monthly Labor Review, September, pp. 3-15. 


\section{RECENT WORKING PAPERS FROM THE CENTER FOR RETIREMENT RESEARCH AT BOSTON COLLEGE}

The Impact of a DROP Program on the Age of Retirement and Employer Pension Costs Samson Alva, Norma B. Coe, and Anthony Webb, September 2010

Housing Consumption in Late Life: The Role of Income, Health Shocks, and Marital Shocks Douglas A. Wolf and Janet M. Wilmoth, September 2010

Adjusting Social Security for Increasing Life Expectancy: Effects on Progressivity Courtney Monk, John A. Turner, and Natalia A. Zhivan, August 2010

Work and Retirement Patterns for the G.I. Generation, Silent Generation, and Early Boomers: Thirty Years of Change

Richard W. Johnson, Barbara A. Butrica, and Corina Mommaerts, July 2010

Spousal Health Shocks and the Timing of the Retirement Decision in the Face of ForwardLooking Financial Incentives

Courtney Harold Van Houtven and Norma B. Coe, June 2010

Incorporating Employee Heterogenity Into Default Rules for Retirement Plan Selection Gopi Shah Godi and Colleen Flaherty Manchester, May 2010

Accurately Measuring Health Over the Life Course

Fabian Lange and Doug McKee, May 2010

Getting to the Top of Mind: How Reminders Increase Saving

Dean Karlan, Margaret McConnell, Sendhil Mullainathan, and Jonathan Zinman, April 2010

The Shrinking Tax Preference for Pension Savings: An Analysis of Income Tax Changes, 1985-2007

Gary Burtless and Eric Toder, March 2010

Social Security, Benefit Claiming and Labor Force Participation: A Quantitative General Equilibrium Approach

Selahattin Imrohoroğlu and Sagiri Kitao, March 2010

How Much Is Enough? The Distribution of Lifetime Health Care Costs

Anthony Webb and Natalia Zhivan, February 2010

Impact of Immigration on the Distribution of American Well-Being

Gary Burtless, December 2009

Actual and Anticipated Inheritance Receipts

Norma B. Coe and Anthony Webb, December 2009

All working papers are available on the Center for Retirement Research website (http://crr.bc.edu) and can be requested by e-mail (crr@bc.edu) or phone (617-552-1762). 